\title{
AC 2010-1783: INVESTIGATION OF COMPUTATIONAL AND VISUAL MODULES TO ENHANCE LEARNING IN UNDERGRADUATE HEAT TRANSFER
}

\section{Nicholas Roberts, Vanderbilt University}

Nick Roberts is a Ph.D. candidate at Vanderbilt University where he researches micro/nano-scale thermal transport in solids and liquids and also serves as a teaching assistant in Thermodynamics and Heat Transfer.

\section{Greg Walker, Vanderbilt University}

Greg Walker is an Associate Professor at Vanderbilt University specializing in Heat Transfer and Energy Conversion in the Department of Mechanical Engineering. 


\title{
AC 2010-1783: Investigation of Computational and Visual Modules to Enhance Learning in Undergraduate Heat Transfer
}

\author{
N.A. Roberts and D.G. Walker \\ Department of Mechanical Engineering \\ Vanderbilt University \\ Nashville, TN USA, 37325
}

\begin{abstract}
Engineering concepts can be difficult for some types of learners when the problem or system under consideration is difficult to visualize. Visual and computational tools can be a useful way to show students the problem thus making it easier to understand. This work looks at how new tools designed for thermalHUB.org can be use in an undergraduate heat transfer course to aid in the understanding and learning of specific concepts and engineering design. ThermalHUB.org is thermal science cyberinfrastructure comprised of community-contributed resources designed for educational applications, professional networking and research simulation tools for heat transfer. These tools allow additional depth and design content to be incorporated into the course. They have been used in the lectures as demonstrations of concepts and sample problems, they have been available as optional resources for assignments and they have been required for some assignments. The results have shown that students participated in a discussion about a concept more often during the demonstrations where they could ask for part of the problem to be changed and be able to see the solution change. The results also showed that when the tools were available, but not required very few students used them unless the tool was appealing for time saving, but when they were required to use the tools they were able to approach the problem and think about the fundamental concepts as opposed to focusing on getting the correct solution. These results show that the visual and computational tools used here were not necessary for many of the problems encountered for homework problems, but attractive for use on design type problems. A fair percentage of the students enjoyed and learned from the in-lecture demonstrations. A small percentage of the students chose to use the tools outside of class to better their understanding of the concepts instead of just learning enough to get the correct solution.
\end{abstract}

\section{Introduction}

The use of technology in the classroom has reduced the work load for instructors and offers the potential for improved learning, but many time the use of technology alone fails to grasp the attention or interest of the students enrolled. Interactive demonstrations, whether computer-based or hands-on, have been shown to enhance comprehension especially when dealing with higher level concepts often encountered in science and engineering courses [1-5]. Though hands-on activities are likely more effective for student learning, in class demonstrations of simulation tools related to 
a current topic are more realistic for the large class sizes encountered in science and engineering classes today. If simulation tools are designed for demonstrations they can be interactive by engaging the students in a discussion about expected solutions or results based on a current problem, especially when the problem involves both the currently topic of the class and a current topic discusses in massive media outlets. Another additional advantage with online simulation tools is that students have the ability to revisit them outside of the classroom while hands-on activities typically only take place in the class or laboratory.

ThermalHUB.org is a thermal-science based website that is dedicated to the advancement of educating and researching thermal-science engineering [6]. It is a National Science Foundation funded project that relies on users to contribute content in the form of simulation tools, paper reviews, teaching and research presentations and wiki pages on specific thermal-science topics. As thermalHUB.org continues to grow more and more educational and research tools we become available for anyone to use from anywhere with an internet connection for no charge. In the current work two educational tools were developed and two existing tools were utilized in and undergraduate heat transfer class to study how the use of the tools 1) in demonstrations in cooperation with standard lectures, 2) as an optional resource for course assignments and 3) as a required resource for course assignments enhanced, it at all, the students understanding and retention of course material.

\section{Approach}

In this study the concepts of equivalent thermal resistance circuits, numerical heat transfer and heat exchangers were chosen as the topics in which tools would be designed, demonstrated and made available to the students. The tools created for this work were a finite different method (FDM) tool for the numerical heat transfer topic [7] and an NTU-effectiveness heat exchanger tool for the heat exchanger topic [8]. The tools utilized that were already in existence were hotSPICE, an equivalent thermal circuit analysis package, for the equivalent thermal resistance circuit topic [9] and an analytic conduction solution tool also used during the numerical heat transfer topic [10].

In order to investigate if and how these simulations tools can be beneficial to students in engineering courses, the study was divided so that one aspect of the tool usage could be examined independently upon completion of the entire study.

The first portion of the work involved the topic of equivalent thermal resistance circuits. For this topic the concept was introduced and example problems were worked using a typical method of writing on the board. In the next scheduled lecture the simulation tool, hotSPICE [9] was introduced to the class via computer and projector. I screen shot of the tool is shown in Figure 1. Once the students understood how the tool worked the same problems were analyzed using via

simulation. With the same set of problems the students were able to interact with the instructor and voice their opinions about what parameters to vary, components to eliminate or add in order to obtain a more energy efficient house and thermal management system for a CPU. Upon completion of these relatively standard examples the tool was then used to solve more complex problems with multiple parallel resistances and parallel boundary conditions to solve for heat loss/gain and temperatures in the systems. Following the coverage of equivalent thermal resistance circuits and the introduction and demonstration of the hotSPICE tool [9] the students were assigned a set of six 


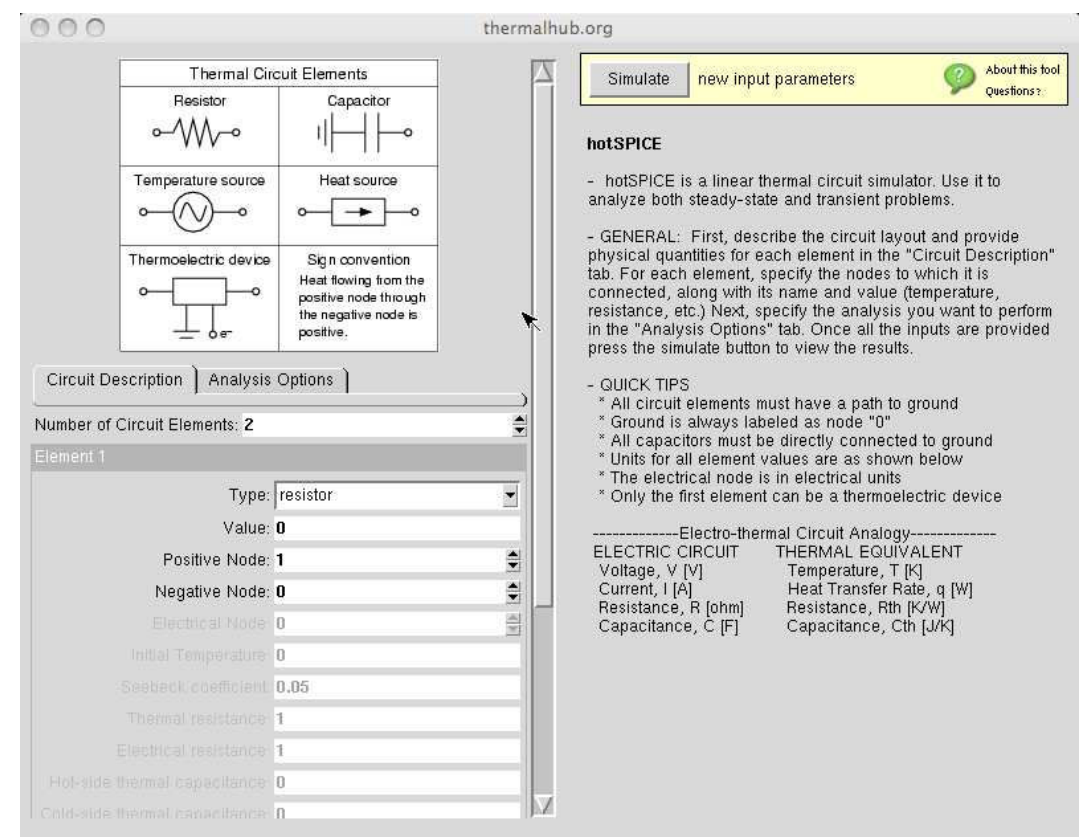

Figure 1: Screen shot of hotSPICE tool on thermalHUB.org

homework problems (See Appendix A). The students were not required and were not asked to use the tool as a resource to complete the homework. This was done to possibly answer the following questions questions: 1) did students willfully use the available tool when not encourage or asked to do so? 2) if students used the tool, how did they use it? 3) if students used the tool, did it help them with the completion of the assignment? and 4) if students did not use the tool, why did they choose not to?

The second section of this study involves the topic of numerical heat transfer. The Finite Difference Method (FDM) was taught in the first half of a lecture period and the 1D finite difference method tool was demonstrated in the second half. The analytic conduction solutions tool was also used in the demonstration and a verification tool. These tools can be seen in Figures 2 and 3. These tools were not only demonstrated to show how the finite difference method works and how it compares to analytic solutions, but these tools also allow the students to look at how initial conditions, boundary conditions, heat generation and material properties change the solution in transient and steady-state problems. In this section of the study no assignments were given to the students, but an optional survey was distributed to ask students about how they felt the in-class demonstrations changed their understanding of the method. On the final exam in the course the students were asked questions about temperature distributions in systems with different boundary conditions, initial conditions, generation and material properties. The results on the exam will then be compared to the results on the same questions from previous semesters.

In the third section of the study the topic of heat exchangers was covered. In this portion of the work the tool was demonstrated to the class at the end of the final lecture on the topic. This tool solves for the NTU or the effectiveness of heat exchanger based on the properties of the fluids 


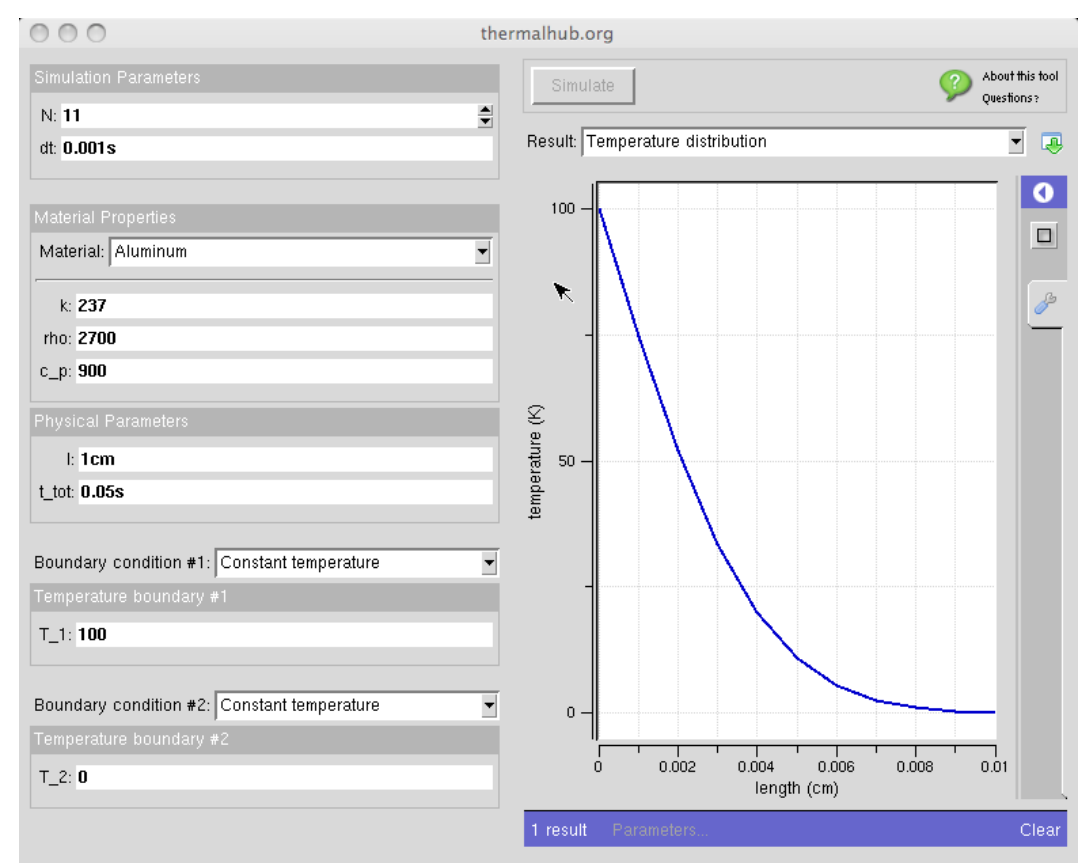

Figure 2: Screen shot of 1D FDM tool on thermalHUB.org

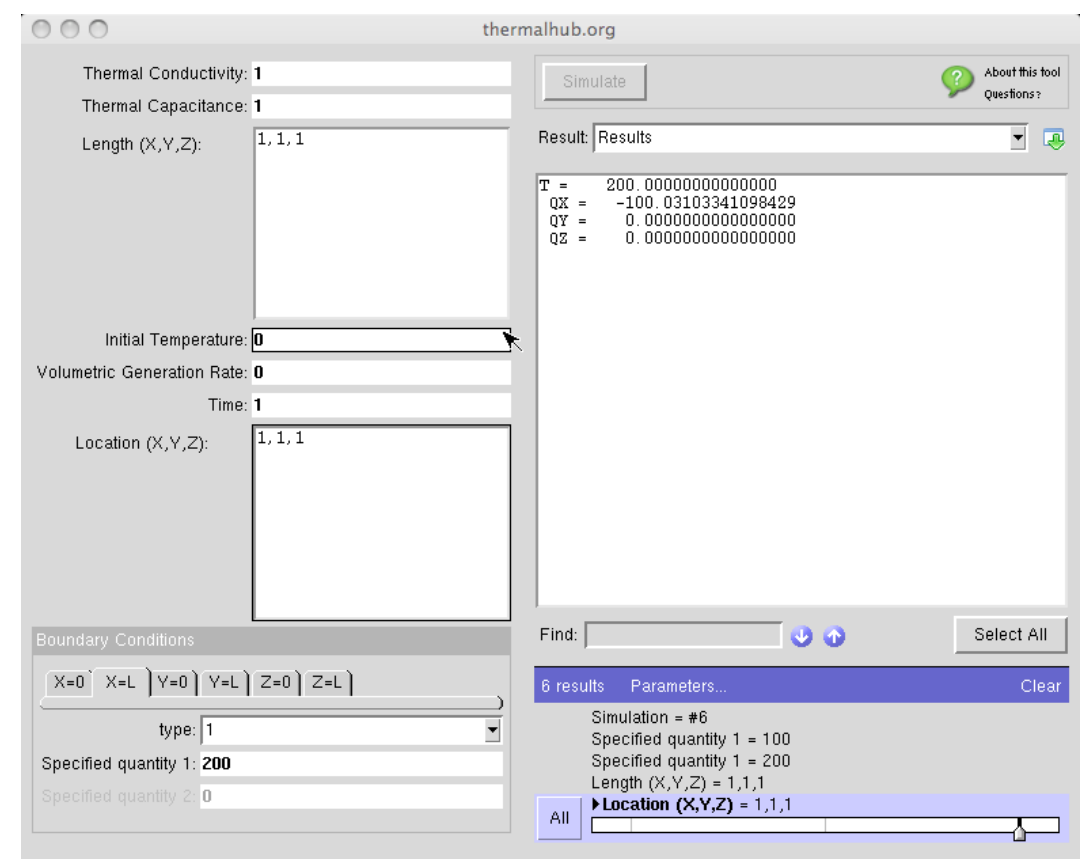

Figure 3: Screen shot of analytic conduction solution tool on thermalHUB.org 


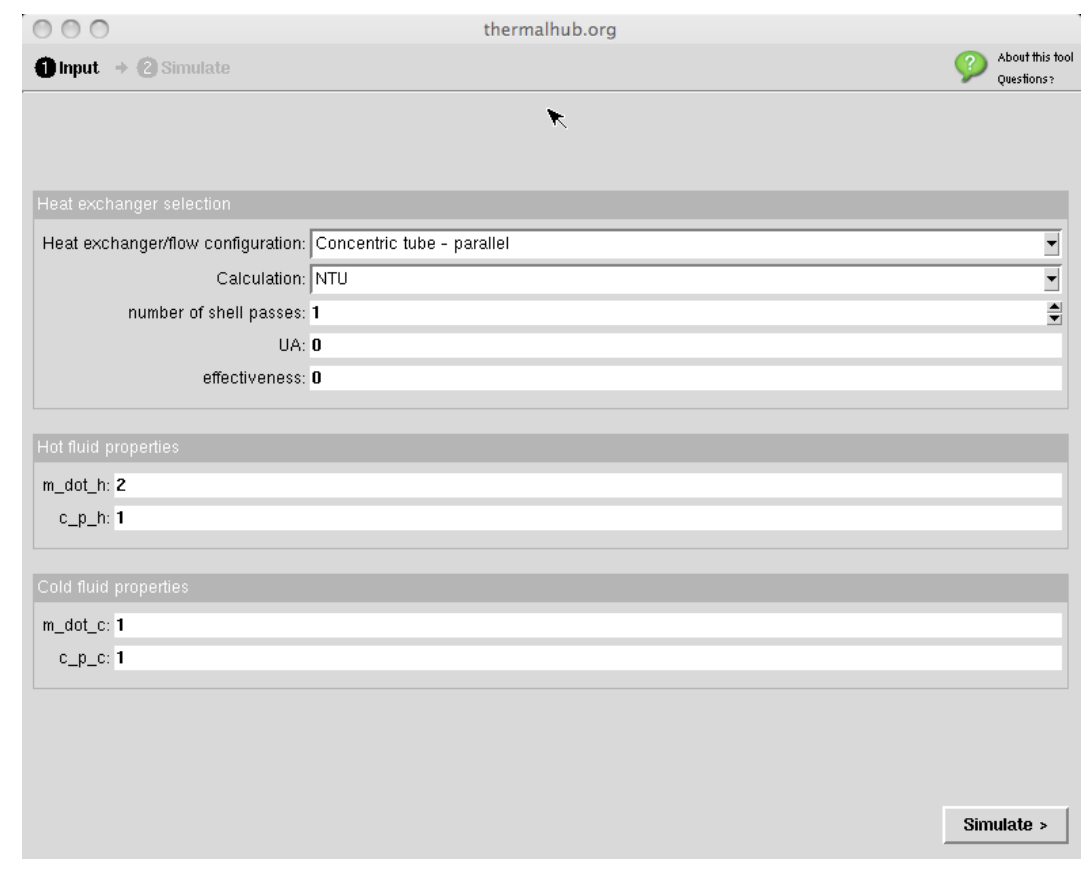

Figure 4: Screen shot of the NTU-effectiveness tool on thermalHUB.org

involved and the configuration of the heat exchanger. A screen shot of this tool can be seen in Figure 4. In the demonstration example problems were worked in which the tool was utilized. The students were then assigned three homework questions in which one specifically asked them to use the NTU-effectiveness tool [8] on thermalHUB.org (see Appendix A for problems). This was done to determine if students would be more likely to use a simulation tool on additional problems if they were previously required to use the tool. Additionally the students were then asked if they felt they benefited from the use of the tool or if it made a difference. Finally the students were assigned a design project where it was their goal to design a heat exchanger based on a specific problem (see Appendix A). The students were not required to use the tool, but they were reminded that this tool could be extremely useful in the design process.

To collect data for this study two optional surveys were distributed to the class of 58 students to obtain their opinions of the tools being incorporated in the course and performance on the design project and final exams were compared to previous semesters. The survey questions are given in the Appendix B.

\section{Results}

The first section of the study involved a demonstration in class of the hotSPICE tool (equivalent thermal resistance circuits) along with a homework assignment. The tool was not advertised for the students to use on the homework to determine if they would use it on their own without a reminder or encouragement. The optional survey was distributed after the homework assignments were collected (see Appendix B). 26 of the 58 students in the class participated in the survey 
and $100 \%$ of them did not use the tool on the homework assignment which agrees well with the findings of Welch [11] which stated that many students do not participate in or take advantage of resources that are not required. $53.8 \%$ of the students that participated in the survey stated that they did not feel the complexity of the problems required additional resources to solve. $23.1 \%$ of the participants stated that they did not think to use the tool or that they either did not know about the tool or forgot it was available. The remaining $23.1 \%$ of the students that participated felt that they did not understand the tool well enough to use it. 50\% of the students that did not understand the tool well enough to use it felt additional tutorial time would have benefited them.

The next section of the study was about numerical heat transfer along with a conceptual discussion of how initial conditions, boundary conditions, heat generation and material properties impacts temperature distributions in systems or solutions to problems. This involved a lecture on the finite difference method and demonstrated a 1D finite difference method tool and an analytic conduction solution tool. Both of these tools were used to solve problems (transient and steady-state) that students may not always be able to solve analytically with their mathematical background. No homework assignment was given for this portion of the work, but the students were asked questions in the second survey (see Appendix B). In this survey the participation was slightly less that the first, having only 24 of the 58 students in the class participate. This drop in participation is likely due to the time of the survey distribution which was after the final exam was distributed. In this case $8.3 \%$ found the demonstrations to be very useful, $16.7 \%$ found the demonstrations to be mostly useful, $41.7 \%$ found the demonstrations to be somewhat useful, $16.7 \%$ found the demonstration to be only partly useful, $0.0 \%$ found the demonstrations to be a waste of time and $16.7 \%$ did not respond to the question. The students were also asked if they used these tools outside of class to help improve their understanding of concepts. $50.0 \%$ of the students responded that they did not use either of the tools outside of class, $33.3 \%$ said they did use the tools outside of class and $16.7 \%$ did not respond to the question. The students that used the tools found they to be useful for them to see how solutions changed with varied materials and boundary conditions and verifying assignments. The students that did not use the tools said they chose not to because they felt they were not needed for a problem or the concept was already understood therefore they would take additional time with no benefit. Finally the students were asked to give their opinions about how to improve the tools and/or lectures in which the tools were demonstrated. Most of the students felt the demonstrations and lectures involving the tools were good, but some felt additional time may be necessary for the students to fully understand how to use the tools. Several of the students also felt the tools could be improved greatly by making them more user friendly and easier to understand without needing a tutorial.

The heat exchanger tool was introduced in the course first through a demonstration at the end of a lecture, it was required on one of three homework problems and was it was an optional resource for a heat exchanger design project. The responses for the lecture demonstrations were given in the last paragraph. 55 students turned in the assignment all of which used the NTU-effectiveness tool on the required problem, but only 6 students, $10.9 \%$, used the tool for the additional one or two problems. This result still seems to show that students are not willing to use these tools unless they are required. This may also be because many of the students felt the assigned problems were not complex enough to warrant the use of the additional resources. The students were also encouraged to use this tool on the design project they were assigned (see Appendix A). Of the 15 
groups working on the design project 9 used the thermalHUB.org NTU-effectiveness tool. The groups that used the tool scored an average of $82.2 \%$ while the ones that did not use the tool scored an average of $80.0 \%$. The real difference in the results was that the 9 groups that used the tool had an average of 3.5 different initial designs while the 6 groups that did not use the tool had an average of 1.5 different initial designs. An important part of engineering design is to start with a larger number of designs and work your way down to the best design. The survey results obtained about the use of the tool are broken downs as follows: $25.0 \%$ of the students that participated felt the NTU-effectiveness tool was very helpful for the design project, $25.0 \%$ felt it was mostly useful, $25.0 \%$ felt it was only somewhat useful, $8.3 \%$ felt it was a waste of time and $16.7 \%$ did not respond to the question. The students were also asked how they felt the tool could be improved for this design project and again the reviews were mixed. A few students again asked for instructions or a more involved tutorial. There were also several students that stated that nothing needed to be changed and that the tool worked perfectly for their project. There was one comment that the tool did not work properly for the student and one comment that stated the tool was too basic for the level of complexity involved in the design process.

Finally exam questions were selected from previous semesters to compare the knowledge of the current class with previous classes. Four questions involved topics that involved the in-class demonstrations and one question did not (baseline). The questions used can be found in Appendix A. The comparison results for the average score on each question is shown in Figure 5. Questions 1, 2, 4 and 5 are the covered topic questions and question 3 is the baseline. Each class was composed of at least 57 students and a maximum of 65 . The same instructor supervised the course and followed the same schedule and rubric. The results show that the current semester students performed better on all the questions, but only slightly better on the baseline question (within the noise). On the questions in-which a tool was used in lecture the students performed much better than previous semester students especially in the more conceptual questions where they were required to draw temperature profiles based on boundary and initial conditions which is a fundamental part of understanding heat transfer.

\section{Conclusions}

The tools used in this work were likely not well designed for solving homework problems, but did seem to be a good resource for design type problems by giving students the ability to quickly sweep through several designs and eliminate the weaker ones. The students also seemed to appreciate the in-class demonstrations, but felt additional time may be required for some of the tools to better understand how they work and how to effectively use them. The current students also showed greater understanding based on the exam questions when compared to previous semesters which is an indication that the in-class demonstrations are beneficial to the students to gain a better conceptual knowledge of heat transfer. In the future the tools and objective of the topic or concept will be tailored to one another making them more effective for lectures/demonstrations and homework or design problems and more care will be given to ensure the students understand how the tools are used. 


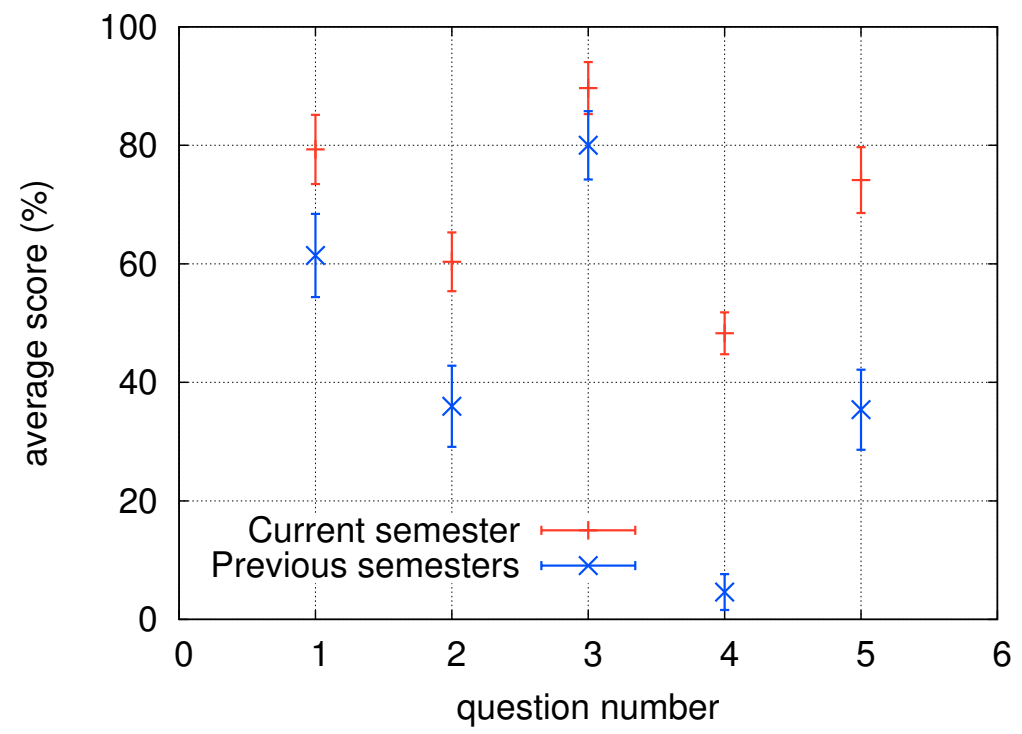

Figure 5: Comparison of exam questions involving topics with and without demonstrations for current and previous semesters. Questions 1, 2, 4 and 5 involve topics related to the tools and question 3 does not.

\section{References}

[1] A.M. Ibrahim, "Economical integration of virtual laboratories in eet curricula", in Proceedings of the 2001 American Society for Engineering Education Annual Conference and Exposition. ASEE, 2001.

[2] D.J. Olinger and J.C. Hermanson, "Integrated thermal-fluid experiments in wpi's discovery classroom”, Journal of Engineering Education, 2002.

[3] W.C Crone, A.B. Ellis, A.C. Payne, K.W. Lux, A.K. Bentley, R.W. Carpick, D. Stone, G.C. Lisensky, and S.M. Condren, "Incorporating concepts of nanotechnology into the materials science and engineering classroom and laboratory", in Proceedings of the 2003 American Society for Engineering Education Annual Conference and Exposition. ASEE, 2003.

[4] R. Hayne, "Beyond vhdl simulation to on-chip testing", ASEE, 2008.

[5] J. Watkins, G. Piper, K. Wedeward, and E. Mitchell, "Computer animation: A visualization tool for dynamic system simulations", ASEE.

[6] T. Fisher, M. McLennan, J. Lukes, G. Walker, L. Shi, M.P. Menguc, S.V. Garimella, C.P. Grigoropoulos, and J. Murthy, "Report from the 2007 thermalhub community planning workshop", https://thermalhub.org/resources/35, Jan 2008.

[7] N.A. Roberts, "1d finite difference method conduction heat transfer tool", https://thermalhub.org/tools/1dfdmht, 2009. 
[8] N.A. Roberts, "Ntu-effectiveness method heat exchanger tool", https://thermalhub.org/tools/ntueffect, 2009.

[9] A. Schwinke and T. Fisher, "hotspice", https://thermalhub.org/tools/hotspice, 2008.

[10] D.G. Walker and J. Vere Beck, "Analytic conduction solutions", https://thermalhub.org/tools/cond3d, 2009.

[11] K.C. Welch, "Perceptions of an introductory tutorial on mathematica software as an addition to an engineering circuits course", in CIRTL-Vanderbilt Symposium, Nashville, TN, January 2009.

\section{A Appendix}

A.1 Equivalent thermal resistance assignment

1. A $2 \mathrm{~cm}$-square cross-section, $10 \mathrm{~cm}$-long bar consists of a $1 \mathrm{~cm}$-thick copper layer and a $1 \mathrm{~cm}$-thick epoxy composite layer. Compare the thermal resistances for heat flow perpendicular and parallel to the layers. In both cases, assume that the two sides of the slab are isothermal. Take $k=400 \mathrm{~W} / \mathrm{mK}$ for the copper and $k=0.4 \mathrm{~W} / \mathrm{mK}$ for the epoxy composite.

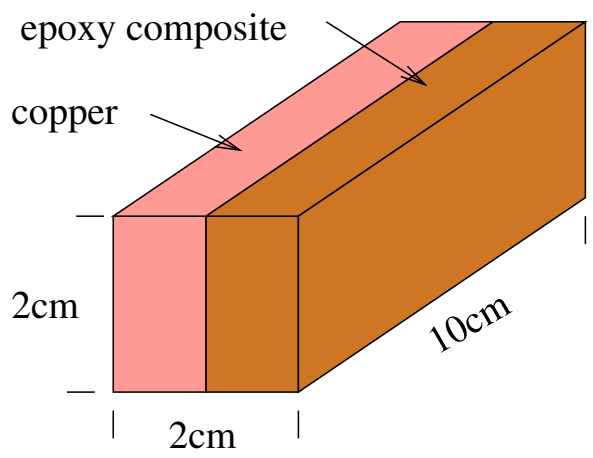

2. A polystyrene ice chest has exterior dimensions $30 \mathrm{~cm} \times 30 \mathrm{~cm} \times 15 \mathrm{~cm}$ deep, and a $3 \mathrm{~cm}$ wall thickness. The chest is filled with ice and water such that the ice is $70 \%$ of the mass initially. The ambient air is $30^{\circ} \mathrm{C}$, and the outside convective heat transfer coefficient is $h=10 \mathrm{~W} / \mathrm{mK}$. If the heat through base is negligible, determine the time required for the ice to melt. Use $\rho=1000 \mathrm{~kg} / \mathrm{m}^{3}$ for the mixture and an enthalpy of melting $h_{s f}=335 \mathrm{~kJ} / \mathrm{kg}$.

3. The thermal conductivity of a solid may often be assumed to vary linearly with temperature, $k=k_{0}\left[1+a\left(T-T_{0}\right)\right]$, where $k=k_{0}$ at the reference temperature $T_{0}$, and $a$ is a constant coefficient. Consider a solid slab. $0<x<L$, with the face at $x=0$ maintained at a temperature $T_{1}$. Determine the temperature profile across the slab in terms of $T_{1}$ and the heat flux $q$. Sketch the profiles for zero, negative and positive coefficients. 
4. A thin computer chip is exposed to a dielectric liquid with $h_{o}=1000 \mathrm{~W} / \mathrm{m}^{2} \mathrm{~K}$ and $T_{0}=$ $20^{\circ} \mathrm{C}$ on one side and is joined to a conductive circuit board on the other. The thermal contact resistance between the chip and the board is $10^{-4} \mathrm{~m}^{2} \mathrm{~K} / \mathrm{W}$, and the board thickness and thermal conductivity are $L_{b}=5 \mathrm{~mm}$ and $k_{b}=1 \mathrm{~W} / \mathrm{m} \mathrm{K}$ respectively. The other surface of the board is exposed to ambient air for which $h_{i}=40 \mathrm{~W} / \mathrm{m}^{2} \mathrm{~K}$ and $T_{i}=20^{\circ} \mathrm{C}$. Under steady-state conditions for which the heat dissipation is $q^{\prime \prime}=30,000 \mathrm{~W} / \mathrm{m}^{2}$, what is the chip temperature?

5. In an experiment to determine the heat transfer coefficient of nanofluids, a thin electric heater is wrapped around the outer surface of a long cylindrical stainless steel tube whose inner surface is maintained at a temperature of $5^{\circ} \mathrm{C}$. The tube wall has inner and outer radii of $35 \mathrm{~mm}$ and $57 \mathrm{~mm}$ respectively. The thermal contact resistance between the heater and the outer surface of the tube is $R^{\prime}=0.01 \mathrm{mK} / \mathrm{W}$. The outer surface of the heater is exposed to a fluid at $T_{\infty}=-10^{\circ} \mathrm{C}$ with $h=100 \mathrm{~W} / \mathrm{m}^{2} \mathrm{~K}$. Determine the heater power per unit length of tube required to maintain the heater at $25^{\circ} \mathrm{C}$.

6. A $5 \mathrm{~kW}$ heater using Nichrome wire is to be designed to heat air to $400 \mathrm{~K}$. The maximum allowable wire temperature is $1500 \mathrm{~K}$, and a minimum heat transfer coefficient of $600 \mathrm{~W} / \mathrm{m}^{2} \mathrm{~K}$ is expected. A variable voltage supply up to $130 \mathrm{~V}$ is available. Determine the length of a $1 \mathrm{~mm}$ diameter wire required. Also check the current and voltage. The electrical resistivity of the Nichrome wire is $100 \mu \Omega \mathrm{cm}$ and its thermal conductivity is $30 \mathrm{~W} / \mathrm{m} \mathrm{K}$.

\section{A.2 Heat exchanger assignment}

1. Calculate the required heat transfer area for the following heat exchanger configurations: a) concentric tube - parallel flow, b) concentric tube - counterflow, c) shell and tube, one-shell pass and two tube passes, d) Cross flow, single pass, both fluids unmixed. Fluid 1 as a specific heat of $3500 \mathrm{~J} / \mathrm{kg}-\mathrm{K}$ and a flow rate of $2 \mathrm{~kg} / \mathrm{s}$ initially at $80 \mathrm{C}$ and needs to be cooled to $50 \mathrm{C}$. Fluid 2 is water with a flow rate of $2.5 \mathrm{~kg} / \mathrm{s}$ initially at $15 \mathrm{C}$. Assume an overall heat transfer coefficient of $2000 \mathrm{~W} / \mathrm{m}^{2} \mathrm{~K}$. Use thermalHUB.org to solve this problem.

2. Find the oil flow rate and length of the tubes required to achieve an outlet temperature of 100 $\mathrm{C}$ with an initial temperature of $160 \mathrm{C}$. The heat exchanger is this case is a shell-and-tube with 10 tubes, each $25 \mathrm{~mm}$ in diameter, making 8 passes and the other fluid is water initially at $15 \mathrm{C}$ and ending at $85 \mathrm{C}$ flowing at $2.5 \mathrm{~kg} / \mathrm{s}$. You can assume the heat transfer coefficient to be $400 \mathrm{~W} / \mathrm{m}^{2} \mathrm{~K}$.

3. Calculate the UA product required for the chilling process and the length $L$ of the exchanger, the outlet temperature of the ground water and the milk outlet temperature for the cases when the water flow rate is halved and doubled using the UA that was previously calculated. The outlet temperature must be below $13 \mathrm{C}$ after passing through a counterflow concentric tube heat exchanger with a $50 \mathrm{~mm}$ diameter inner pipe and an overall heat transfer coefficient of $1000 \mathrm{~W} / \mathrm{m}^{2} \mathrm{~K}$. The initial temperature of the milk is $38.6 \mathrm{C}$ flowing at a rate of $250 \mathrm{liter} / \mathrm{h}$. The water is initially at $10 \mathrm{C}$ flowing at a rate of $0.72 \mathrm{~m}^{3} / \mathrm{h}$. 


\section{A.3 Heat exchanger design project}

To save money on your gas bill you decide to design a heat recovery system for your shower that uses the waste water going down the drain to heat the cold water prior to mixing with the hot water. The hot water supply $45^{\circ} \mathrm{C}$, the cold supply is $10^{\circ} \mathrm{C}$ and the total flow rate out the shower head is $1.5 \mathrm{gpm}$. If the desired shower temperature is $35^{\circ} \mathrm{C}$, design a heat exchanger to recover the thermal energy in the drain water. Consider multiple designs/configurations of the heat exchanger and comment why you chose to use your design. Calculate the area required for your configuration and design, provide sketches of your design. For this design you will need to determine the convective heat transfer coefficients and you are encouraged to use the NTUeffectiveness tool on thermalHUB to assist with the design. Estimate the cost savings of the heat exchanger. What other design criteria should be considered?

You should work in self-selected teams of four to five students. Your final report should be typed and include plots of any analysis. Detailed calculations can be hand-written if necessary.

\section{A.4 Exam problems}

1. What is the minimum thickness of Styrofoam $(k=0.03 \mathrm{~W} / \mathrm{mK}$ needed to ensure a heat load of less than $800 \mathrm{~W}$ for a $2 \mathrm{~m}$ (on all sides) refrigerator if the inner and outer surfaces are $-10 \mathrm{C}$ and $35 \mathrm{C}$, respectively? (Equivalent thermal resistance circuits - hotSPICE tool)

2. Sketch the temperature distribution in a plane wall where the right side is insulated, the left side convects and $q^{\prime \prime \prime}<0$. (Temperature distributions - FDM and analytic conduction solutions tools)

3. How does the Nusselt number change as a function of $x$ in pipe flow ( $x$ is the axial direction)? (Baseline)

4. Draw three isotherms (at approximately equal temperature intervals) on a two-dimensional square plate given the following boundary conditions: $T_{l}=0, T_{2}=0, q_{t}=1, q_{b}=0$. (Note that $l, r, t$ and $b$ stand for left, right, top and bottom, respectively.) (Temperature distributions and boundary conditions - FDM and analytic conduction solutions tools)

5. Draw the temperature distribution in a semi-infinite slab, where the initial temperature $\left(T_{i}\right)$ is uniform, after a short time and a long time for the given conditions: $\left|q^{\prime \prime}(x=0)\right|=$ $h\left(T_{s}-T_{\text {inf }}\right)$. (Temperature distributions, initial conditions and boundary conditions - FDM and analytic conduction solutions tools)

\section{B Appendix}

\section{B.1 Survey 1 questions}

1. Did you use the thermalHUB.org tool (hotSPICE) to complete any or part of equivalent thermal resistance homework problems?

2. If you did, did you find it useful? 
3. If you did not, why did you choose to not use it?

B.2 Survey 2 questions

1. How useful did you find the in-class demonstrations of the thermalHUB.org tools as supplementary information to the lectures when they were used?

2. How useful did you find the thermalHUB.org tools for homework assignments when applicable?

3. How useful did you find the thermalHUB.org tools for the design project?

4. Did you use any of the tools when they were not required (on homework assignments or to improve your understanding of a concept)?

5. If you did, what tool(s) did you use and how did you use them?

6. If you did not, what was the reason you did not?

7. Is there anything you would change to improve their usefulness in lectures?

8. Is there anything you would change to improve their usefulness in homeworks?

9. Is there anything you would change to improve their usefulness in the design project? 